\title{
Role of Tumor Necrosis Factor Alpha Promoter Polymorphisms in Interferon Related Side Effects in Chronic Hepatitis B Patients Under Interferon Alpha $\mathbf{2 b}$ Ireatment
}

\author{
Ahmet Çağkan İnkaya ${ }^{1, *}$, [MD] \\ ORCID: 0000-0001-7943-8715 \\ Emel Türk Arıbaş ${ }^{1},[\mathrm{MD}]$ \\ ORCID: 0000-0002-4551-413 \\ Bahar Kandemir ${ }^{1}$, [MD] \\ ORCID: 0000-0002-9815-8767 \\ Hasan Acar ${ }^{3}$, [PhD] \\ ORCID: 0000-0003-1888-2657 \\ Mehmet Bitirgen ${ }^{1}$, [MD] \\ ORCID: 0000-0002-3105-8665
}

1.Selçuk University Meram Medical Faculty Department of Clinical Bacteriology and Infectious Diseases, 42080, Meram, Konya, Turkey

2.Hacettepe University School of Medicine Department of Infectious Diseases Sihhıye, Ankara, Turkey

3.Selçuk University Meram Medical Faculty Department of Molecular Biology and Genetics, Konya, Turkey

*Corresponding Author: Ahmet Çağkan İnkaya, MD

Hacettepe University School of Medicine

Department of Infectious Diseases

Sinhıye, 06100, Ankara, Turkey

inkaya@hacettepe.edu.tr,

\section{nee ABSTRACT Cem}

Objective: Interferon alpha therapy is associated with series of adverse effects leading premature discontinuation of treatment. Here we aimed to determine the effects of Tumor necrosis alpha promoter polymorphisms on interferon related side effects during interferon alpha $2 \mathrm{~b}$ treatment in chronic hepatitis B patients.

Material and Methods: This observational study enrolled 50 chronic hepatitis $B$ patients, who were treated with interferon alpha $2 \mathrm{~b} 10$ tiw plus lamivudine 100mg/day at Selçuk University Meram Medical Faculty Department of Infectious Diseases and Clinical Bacteriology between 2006-2007. Patients were followed-up with complete blood count, transaminases and amylase monthly at out patient clinics of our department. All patients were asked to fill a questionnaire to evaluate the interferon related side effects at every visit. Tumor necrosis factor alpha -238 and -308 polymorphisms were investigated with PCR-Restriction fragment length polymorphisms.

Results: Arthralgia was present in $93.8 \%$ of patients. Exhaustion, loss of appetite, mount dryness and fever are the leading complaints of the patients. Median complaint scores were $9,9.5,11$ and 5 at $4^{\text {th }}, 12^{\text {th }}, 24^{\text {th }}$ and $48^{\text {th }}$ week visits, respectively. Thrombocytopenia and leucopenia were detected in 8 (16\%) and $5(10 \%)$ patients, respectively. One-third of the patients reported depressive mood however, depression was diagnosed in 5 (10\%) patients. TNF alpha promoter 238GG and 308GG allele was present in 42/50 and $43 / 50$ patients, respectively. No association was found between TNF promoter allele and certain patient-reported side effect, complaint score, hematological and psychological adverse effects.

Conclusion: TNF alpha promoter polymorphisms do not contribute to occurrence of IFN alpha treatment related side effects.

Keywords: TNF alpha promoter polymorphism, interferon alpha, interferon related side effect, chronic hepatitis B

\section{INTRODUCTION}

There are more than 300 million people are chronically infected with hepatitis B virus (HBV) worldwide. Chronic viral hepatitis $B(C H B)$ infection is associated with increased risk of liver-related morbidity, including cirrhosis, fulminant liver failure, liver transplantation, hepatocellular carcinoma (HCC) and death $[1,2]$. In the Americas, HBV prevalence is relatively low, with hepatitis B surface antigen ( $\mathrm{HBsAg})$ positivity ranging from $\leq 2 \%$ to $7 \%$ compared with 
Asia, Africa and the Middle East, where HBV prevalence rates reach $5-20 \%$ of the general population $[2,3]$. Successful implementation of childhood HBV vaccination program in Turkey led to rapid decrease in $\mathrm{HBsAg}$ prevalence. Estimated number of Turkish $\mathrm{CHB}$ patients is 3.3 million with an overall prevalence of $4.7 \%$ [4].

Scaring outcomes of $\mathrm{CHB}$ infection necessitates an effective therapy. The main goal of CHB treatment is to suppress HBV replication and to induce remission of liver disease which in turn will prevent the development of cirrhosis or HCC. In 2006, interferon alpha (IFNa), lamivudine, entecavir, tenofovir and telbivudine were approved and available on market for CHB treatment.

Interferons are pleiotropic proteins, able to initiate and regulate a variety of responses, either directly or by stimulating the induction/activation of additional proteins. Different interferon subtypes intrinsically have the ability to stimulate different but overlapping sets of genes [5]. IFNa has wide variety of side effects on different organ systems which some times lead to premature discontinuations. Treatment with IFNa elicits an immune response leading to secretion of tumor necrosis factor alpha (TNFa), interleukin 1 (IL1) and interleukin 6 (IL6). These cytokines cause fever, chills and behavioral changes [6]. TNFa gene is mapped to the class III region of MHC between HLA-B and DR loci. Several single nucleotide polymorphisms, at TNFa promoter region, effecting TNFa's transcription level were previously demonstrated [7].

Treatment of CHB with IFNa results in ever-complaining patients. Otherwise healthy patients become ill after IFNa administration. On the other hand, IFNa is the most effective agent in terms of $\mathrm{HBs} A g$ clearance which gives it a pivotal role in $\mathrm{CHB}$ treatment. This study was planned in order to determine the role of different TNFa promoter polymorphisms in IFNa treatment-related side effects in CHB patients.

\section{MATERIALS and METHODS}

This single center, prospective, observational study carried out at Selçuk University Meram Faculty of Medicine Department of Infectious Diseases and Clinical Bacteriology between 2006-2007. Ethics committee of Selçuk University Meram Faculty of Medicine reviewed and approved the study protocol (Decision: 12.02.2006, 2006/043). All patients provided written informed consent before undergoing study procedures. The study was carried out in accordance with the Declaration of Helsinki and its amendments.

\section{Patients}

Fifty $\mathrm{CHB}$ patients followed-up at outpatient clinics of Selçuk University Infectious Disease Department were enrolled in this study. CHB diagnosed based on positive HBsAg over 6 months, elevated alanine aminotransferase and aspartate aminotransferase levels and positive antiHBc lgG type antibodies. All patients were screened for $\mathrm{HBeAg}$ antigen and antiHBe antibody. Hepatitis C, Hepatitis D, human immunodeficiency virus infection, autoimmune hepatitis, heavy alcohol consumption (over $40 \mathrm{~g} /$ day) and cirrhosis were exclusion criteria. HBV DNA was measured with real time PCR. All patients underwent liver biopsy. Liver histology was evaluated according to modified Knodells' score. Thyroid function tests were performed before treatment. CHB patients were treated with interferon alpha $2 b$ (ScheringPlough, USA) 10MU tiw plus lamivudine (Glaxo Smith Kline, USA) 100mg/day for 48 weeks.

\section{Patient Follow-up}

All patients were followed-up monthly in out-patient clinics of our department for treatment outcome and side effects. During the follow up visit patient was asked to report any adverse effect which he/she encountered since last visit. Furthermore, a questionnaire was applied to all patients to ease their adverse-effect reporting. Questionnaire was consisted of 28 questions interrogating subjective complaints of patients including chills, fever, myalgia, arthralgia, headache, exhaustion, lethargy, loss of appetite, loss of taste, weight-loss, nausea, vomiting, diarrhea, mouth dryness, forgetfulness, insomnia, convulsion, irritability, paresthesia, loss of hair, chest pain, cough, impotency, chest pain, herpes labialis, depressed mood, palpitation, dyspnea, itching. A complaint score was calculated as each patient-stated complaint scored 1 point. Complaint score calculated at 4th, 12th, 24th and 48th week visits. Median complaint scores were calculated and patients were reclassified with respect to this value as complainers and non-complainers. Difference between these two groups with respect to TNFa promoter polymorphisms was investigated. Complete blood count, transaminases, bilirubin, albumin, urea and creatinine values were evaluated at every visit. HBV DNA levels were measured four times a year $(4,12,24$ and 48 weeks). Thyroid 
function tests were done when needed. Any complaint, which had any other possible explanation, was excluded. Leucopenia was defined as absolute neutrophil count below $1000 / \mathrm{mm} 3$ and thrombocytopenia was defined platelet count below 100000/ $\mathrm{mm} 3$. Interferon induced thyroiditis was diagnosed with thyroid function tests, positive anti-thyroglobulin, anti-thyroid antibodies, thyroid ultrasonography and, when needed, thyroid scintigraphy. Psychiatric evaluation of patients was done when needed. Depressive mood was a patient defined phenomenon whereas, interferon induced depression was diagnosed and treated by an experienced psychiatrist with respect to DSM IV.

\section{PCR-RFLP of TNFa Promoter}

$2 \mathrm{ml}$ of venous blood samples were drawn from all recruited subjects and stored at $4^{\circ} \mathrm{C}$ until DNA isolation. Genomic DNA was isolated from peripheral blood leucocytes using standard phenol-chloroform methods. Isolated DNA was kept at $-80^{\circ} \mathrm{C}$.

Table 1. Outline of TNFa promoter genotyping
Gene fragments containing the polymorphic sites were amplified by PCR. PCR was performed in a $20 \mu \mathrm{L}$ reaction mixture containing $0.4 \mu \mathrm{L}$ DNA Taq polymerase (Fermentas, England), $50 \mathrm{ng}$ genomic DNA, $20 \mu \mathrm{L} 10 \times$ buffer, and $1.5 \mathrm{mmol} / \mathrm{L} \mathrm{MgCl2}$, $1.2 \mu \mathrm{L}$ primers and $10 \mathrm{pmol} / \mathrm{L}$ dNTPs. The PCR cycles were as follows: $94^{\circ} \mathrm{C}$ for 3 minutes, 30 cycles of denaturing at $94^{\circ} \mathrm{C}$ for 15 seconds, annealing at $57^{\circ} \mathrm{C}$ for 15 seconds, extension at $72{ }^{\circ} \mathrm{C}$ for 15 seconds, and a single final extension at $72{ }^{\circ} \mathrm{C}$ for 3 minutes in Applied Biosystems GeneAmp PCR System model 2700 thermocycler. After amplification, products were identified under ultraviolet light after electrophoresis in 3\% agarose gel stained by ethidium bromide (EB). Then PCR products were digested by allele-specific restriction enzymes (Ncol, Fermentas, England) (Mspl Promega, USA) overnight at $37^{\circ} \mathrm{C}$. Cleaved DNA fragments were then identified by ultraviolet light after electrophoresis in 3\% agarose gel stained by EB. pBR322 DNA/BsuRI (Fermentas, England) DNA ladder was used during analysis. TNFa promoter genotyping was reviewed in Table 1.

\begin{tabular}{|l|c|c|c|c|}
\hline Loci & Primer sequences $\left(5^{\prime}\right.$ to $\left.3^{\prime}\right)$ & PCR Product & $\begin{array}{c}\text { Restriction } \\
\text { enzyme }\end{array}$ & Genotype \\
\hline 238 & F:AGAAGACCCCCCTCG GAAC & $152 \mathrm{bp}$ & Mspl & $\begin{array}{c}\text { GG:132+20 bp } \\
-\end{array}$ \\
\hline & F:ATCTGGAGGAAGCGG TAGTG & & & GA:152+132+20 bp \\
308 & R:TCCTCCCTGCTCCGATTCCG & & Ncol $152 \mathrm{bp}$ \\
& & & & GG:87+20 bp \\
\hline
\end{tabular}

\section{Statistical Analysis}

Data were evaluated by $x 2$ test using SPSS 10.0 programme with $\mathrm{p} \leq 0.05$ as statistical significance.

\section{RESULTS}

\section{Patient Characteristics}

Total 50 patients ( 38 men, 12 women) were enrolled in this study. Mean age of the study groups was $36.7 \pm 11.8$. Two patients were lost in follow-up that is why total 48 patients were included in statistical analyses.

\section{Side Effects}

Most common side effect was arthralgia observed in $93.8 \%$ of patients. Exhaustion, loss of appetite, mount dryness and fever were the leading complaints of the patients. Convulsion was not observed. Complaints of the patients were reviewed at Table 2. Median complaint score was 9, 9.5, 11 and 5 at 4th, 12th, 24th and 48th week visits respectively. TNF alpha promoter $238 \mathrm{GG}$ and $308 \mathrm{GG}$ allele was present in $42(84 \%)$ and $43(86 \%)$ patients, respectively. No statistically significant difference detected between certain TNF alpha promoter polymorphism and complainer (C) and non-complainer (NC) groups. Results of genotypic analyses are summarized in Table 3. 
Table 2: Review of patient reported side-effects in $\mathrm{CHB}$ patients receiving interferon alpha $2 \mathrm{~b}$

\begin{tabular}{|c|c|c|c|}
\hline Side Effect & Positive $\%$ & Side Effect & Positive $\%$ \\
\hline Arthralgia & 93.8 & Itching & 60.4 \\
\hline Exhaustion & 89.6 & Paresthesia & 58.3 \\
\hline Loss of appetite & 85.4 & Herpes labialis & 52.1 \\
\hline Mouth Dryness & 85.4 & Insomnia & 52.1 \\
\hline Fever & 83.3 & Nausea & 50 \\
\hline Myalgia & 83.3 & Cough & 45.8 \\
\hline Headache & 81.3 & Chest pain & 43.8 \\
\hline Loss of taste & 77.1 & Impotence & 43.8 \\
\hline Weight-loss & 75 & Depressed mood & 33.3 \\
\hline Lethargy & 72.9 & Dyspnea & 29.2 \\
\hline Loss of hair & 72.9 & Palpitation & 25 \\
\hline Chills & 68.8 & Vomiting & 22.9 \\
\hline Irritability & 66.7 & Diarrhea & 20.8 \\
\hline Forgetfulness & 62.5 & Convulsion & 0 \\
\hline
\end{tabular}

Table 3: Prevalence of TNFa promoter polymorphisms in complainer (C) and non-complainer (NC) groups.

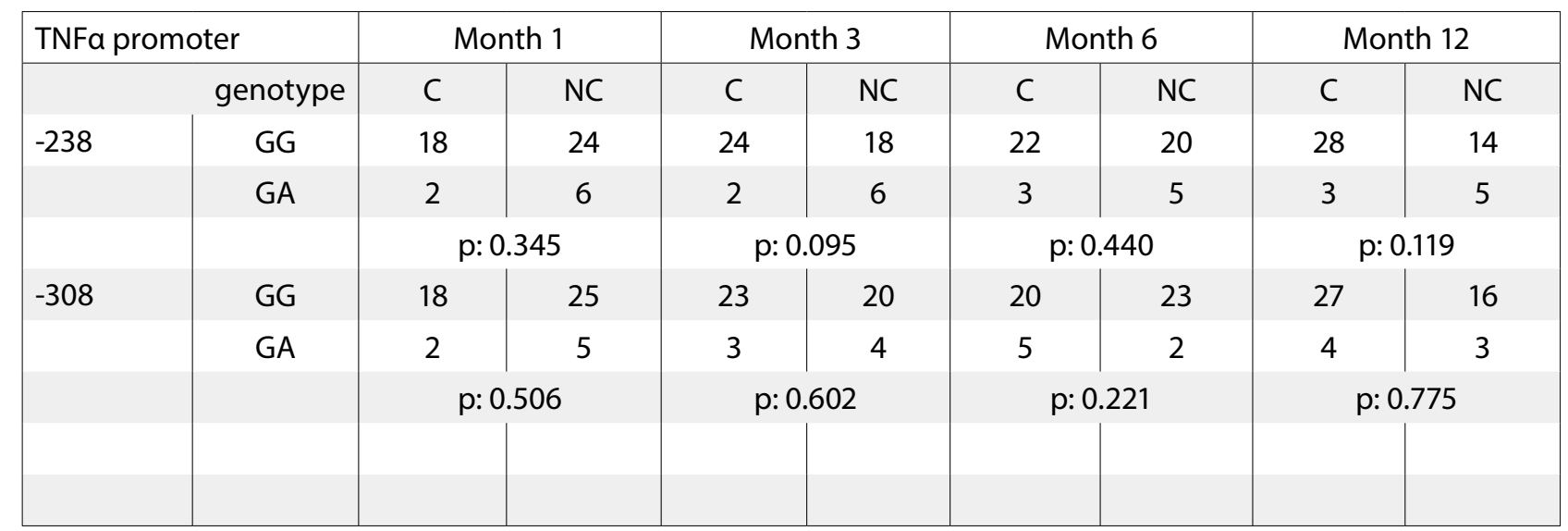

\section{Hematological Side Effects}

Thrombocytopenia and leucopenia diagnosed in 8 (16\%) and 5 (10\%) patients, respectively. No statistically significant association was present between a hematological side effect and TNF promoter polymorphisms (Table 4).

Table 4: Hematological side effects of interferon alpha 2b with respect to TNF promoter polymorphisms.

\begin{tabular}{|l|c|c|c|c|c|}
\hline \multicolumn{6}{|l|}{ TNFa promoter } \\
\hline \multirow{3}{*}{-238} & genotype & Thrombocytopenia & Normal & Leucopenia & Normal \\
& GG & 7 & 35 & 3 & 39 \\
& GA & 1 & 7 & 2 & 6 \\
-308 & & & p: 0.768 & & p: 0.123 \\
& GG & 7 & 36 & 4 & 39 \\
& GA & 1 & 6 & 1 & 6 \\
\hline
\end{tabular}


Psychiatric Side Effects

One-third of the patients suffered depressive mood but depression was diagnosed in 5 (10\%) patients. Patients complaining from depressive mood did not differ from others with respect to TNFa polymorphisms (Table 5).

Table 3. Comparison of risk factors of patients according to complication groups.

\begin{tabular}{|l|c|c|c|c|c|}
\hline \multicolumn{5}{|l|}{ TNFa promoter } \\
\hline \multirow{3}{*}{-238} & genotype & Depressive Mood & Normal & Depression & Normal \\
& GG & 14 & 27 & 4 & 38 \\
& GA & 2 & 5 & 1 & 7 \\
\hline-308 & & & $p: 0.772$ & & p: 0.797 \\
& GG & 13 & 28 & 4 & 39 \\
& GA & 3 & 4 & 1 & 6 \\
\hline
\end{tabular}

\section{DISCUSSION}

IFN-alpha, which has both antiviral and immunomodulatory activities, was the first agent approved for the treatment of both $\mathrm{HBeAg}$-positive and $\mathrm{HBeAg}$ negative $\mathrm{CHB}$ [8]. The main advantage of IFN-a therapy is a finite-duration and sustained off-therapy responses in a proportion of patients with $\mathrm{HBeAg}$ negative CHB [9]. Furthermore, serum half-life of IFNa was boosted as a result of pegylation technology and pegylated forms of IFNa has been widely implemented in CHB treatment [9]. Interferon and pegylated forms are associated with better virological outcomes when compared to nucleoside/nucleotide based antiviral treatment [9]. Conversely, poor tolerability due to frequent and potentially severe side effects is the main drawback of treatment [10]. Side effects of IFNa treatment may lead to dose reduction or premature withdrawals from treatment regime. Side effects of IFNa treatment changes from person to person, suggesting a genetic susceptibility to IFNa induced side effects.

TNFa is cytokine capable with versatile functions. Nevertheless, when TNFa is present in peripheral circulation, it always induces inflammatory phenotype. Despite inflammation is key to overcome infections, number of studies proved the role of TNFa in variety of conditions including autoimmunity $[11,12]$.

Impact of interferon administration in addition to antiviral treatment attracted many scientists all around the world due to unmet needs in CHB treatment $[13,14]$. It has been shown that addition of IFNa to lamivudine lower the rates of emerging lamivudine resistance [14]. Treatment outcomes can be affected by treatment duration, definition of treatment success, ethnic background, infection mode, patient demographics as well as virus itself [14]. Nevertheless, all trials have focused on the treatment success rather than focusing on patient reported outcomes and adverse events.

In this trial we focused on patient reported outcomes. To our knowledge this is the first study in literature exploring certain polymorphisms with regard to patient reported outcomes in CHB treatment. We observed arthralgia, exhaustion, loss of appetite and mount dryness in majority of IFNa treated patients. Patient-reported-fever was present in $83.3 \%$ of patients. Acute toxicity of IFNa treatment consists of fever, myalgia, headache and chills. Flu like symptoms associated with IFNa therapy is found to be associated with TNFa, IL1 and IL6 secretion [6]. In addition to cytokine activation, prostaglandin E2 induction usually occurs during interferon treatment [15]. Effective suppression of prostaglandin E2 by antipyretic agents may alleviate the symptoms triggered by IFNa administration. In this trial, patients were extensively informed on the possible side effects of IFNa and left free to take paracetamol when needed that is why fever was found lesser than other acute side effects. Fever was effectively controlled with paracetamol treatment, whilst arthralgia was not. In this study we evaluated the role of two different polymorphisms of TNFa gene promoter on IFNa induced side effects. We found that TNFa promoter polymorphisms did not contribute to development of acute interferon related toxicities in $\mathrm{CHB}$ patients treated with IFNa. 
Our observations in complaint rates were in consistent with previous findings [6,14]. In addition, our results proved complaint-rate was highest at 24th week and lowest at the end of 48th week suggestive of getting-used-to treatment as time passes by. Our findings suggest that TNFa promoter polymorphisms was not associated with complaint-rate at any time point.

Hematological side effects under interferon treatment is common and dose limiting [6]. In patients treated with low dose IFNa grade 3-4 bone marrow toxicity was low, occurring in $10-15 \%$ of patients [15]. Thrombocytopenia and anemia gradually increases over time under IFNa treatment. Mechanisms underlying hematological side effects include IFNa induced bone marrow inhibition, maturation block, up-regulation of endothelial adhesion molecules which in turn leads to redistribution of blood cells to other compartments and induction of autoimmunity [6]. In this trial, thrombocytopenia and leucopenia was detected in $16 \%$ and $10 \%$ of patients, respectively. Hematological manifestations did not lead to premature discontinuations. We found that, TNFa promoter polymorphisms at position -238 and -308 did not contribute to leucopenia and thrombocytopenia. Thrombocytopenia and leucopenia could be resulted because of redistribution rather than TNF mediated myelosuppresion under IFNa treatment.

Psychiatric symptoms are common among CHB patients [17] and studies with major depression revealed elevated TNFa levels in the sera of patients suggesting a mild inflammatory response [18]. Elevated serum TNFa levels were found in IFNa induced depression [18]. IFNa treatment may result in cognitive, behavioral and affective disturbances and lead to major depression, concentration difficulties and anxiety [17]. IFNa induced depression was more common among Caucasians when compared to Asian population [19]. Depression and premature discontinuations occur in $4-5 \%$ and $6-8 \%$ of CHB patients undergoing IFNa treatment, respectively [20]. In this study we found that 16 out of 48 patients complained from depressive mood whereas, only 5 patients $(10.4 \%)$ were diagnosed to have depression. TNFa -238 and TNFa- 308 genotypes did not confer to development of depressive mood or depression. This finding could be explained by induction of other cytokines rather than TNFa played crucial role in IFNa induced depression.

TNFa levels are subject to control at transcriptional, translational and posttranslational levels. Transcriptional control of TNFa gene can be managed at promoter region of the gene [21]. Some studies showed variable TNFa production upon antigenic stimuli in different promoter genotypes. Polymorphisms at TNFa promoter region -238 and -308 , may confer to differential TNF production in-vivo $[22,23]$. Certain polymorphisms of TNFa promoter may contribute to viral clearance, response to $H B V$ vaccination and disease severity [21, 24]. In this study we evaluated the role of TNFa promoter polymorphisms in IFN induced side effects. No association was found between TNFa genotype and leucopenia, thrombocytopenia, depression, depressive mood and median complaint values.

Our study has some limitations. First it is a single center study enrolled limited number of CHB patients. Thus, results of our study may not be applicable to diverse clinic settings. Furthermore, we might have overlooked the possible association with TNFa promoter polymorphisms due to limited sample size.

As interferon is still the only definitive and finite treatment for $\mathrm{CHB}$ and may result in diverse side effects, treating physician desires to foresee the outcome of therapy: Who will respond? Who will fail in IFN treatment? These questions are still waiting their answers. Microbiological factors are known to influence the outcome of the infection but, host factors are still remains obscure. Many studies are needed to clarify the questions: Who will benefit from treatment and who will develop adverse reactions?

\section{ACKNOWLEDGEMENT}

Authors are pleased to extent their sincere gratitude to the volunteering patients who contributed to this study. Without their enthusiastic involvement this study was destined to fail.

\section{CONFLICT OF INTEREST}

Authors declare no conflict of interest regarding this manuscript 
[1] Lavanchy D. Hepatitis B virus epidemiology, disease burden, treatment, and current and emerging prevention and control measures. J Viral Hepat 2004; 11: 97-107.

[2] World Health Organization. Hepatitis B Fact Sheet No. 204 Revised October 2000.

[3] Lok AS, Heathcote EJ, Hoofnagle JH. Management of hepatitis B: 2000-summary of a workshop. Gastroenterol 2001; 120: 1828-1853.

[4] Özkan, H. Epidemiology of Chronic Hepatitis B in Turkey. Euroasian J Hepato-Gastroenterol 2018; 8: 73-76.

[5] Thomas H, Foster G, Platis D. Mechanisms of action of interferon and nucleoside analogues. J Hepatol 2003; 39: S93-S98.

[6] Sleijfer S, Bannink M, Van Gool AR, et al. Side effects of interferon-a therapy. Pharm World Sci 2005; 27: 423-431.

[7] D'Alfonso S, Richiardi PM. A polymorphic variation in a putative regulation box of the TNFA promoter region. Immunogenetics 1994; 39: 150-4.

[8] Hadziyannis SJ, and Papatheodoridis GV. Hepatitis B e Antigen-Negative Chronic Hepatitis B: Natural History and Treatment. Semin Liver Dis 2006; 26: 130-141.

[9] Chuaypen N, Posuwan, N, Chittmittraprap S, et al. Predictive role of serum $\mathrm{HBsAg}$ and $\mathrm{HBeAg}$ kinetics in patients with $\mathrm{HBeAg}$-negative chronic hepatitis $B$ receiving pegylated interferon-based therapy. Clin Microbiol Inf 2018; 24(3): 306-e7.

[10] Bourlière $M$, Rabiega $P$, Ganne-Carrie $N$, et al. Effect on $\mathrm{HBs}$ antigen clearance of addition of pegylated interferon alfa-2a to nucleos ( $t$ ) ide analogue therapy versus nucleos $(\mathrm{t})$ ide analogue therapy alone in patients with $\mathrm{HBe}$ antigen-negative chronic hepatitis $B$ and sustained undetectable plasma hepatitis B virus DNA: a randomised, controlled, open-label trial. Lancet Gastroenterol Hepatol 2017; 2(3): 177-188.

[11] Azhari H, Swain MG, Role of Peripheral Inflammation in Hepatic Encephalopathy, Clin Exp Hepatol 2018; 8(3):281-285.

[12] Cabal-Hierro L, Lazo PS. Signal transduction by tumor necrosis factor receptors Cellular signalling 2012; 24(6): 1297-1305.

[13] Santantonio T, Niro GA, Sinisi E, et al. Lamivudine/interferon combination therapy in anti-HBe positive chronic hepatitis B patients: a controlled pilot study. J Hepatol 2002;
36: 799-804.

[14] Yuki N, Nagaoka T, Nukui K, et al. Adding interferon to lamivudine enhances the early virologic response and reversion of the precore mutation in difficult-to-treat HBV infection J Gastroenterol 2008; 43(6): 457-463.

[15] Dinarello CA, Bernheim HA, Duff GW, et al. Mechanisms of fever induced by recombinant interferon. J Clin Invest 1984; 74(3): 906-13.

[16] Cameron DA, Cornbleet MC, Mackie RM, et al. Adjuvant interferon alpha $2 \mathrm{~b}$ in high risk melanoma - the Scottish study. Br J Cancer 2001; 84(9): 1146-9.

[17] Aktug-Demir N, Celik M., Kölgelier S, et al. Comparison of the level of depression and anxiety in inactive hepatitis $B$ carriers and chronic hepatitis B patients. Turk Psikiyatri Dergisi 2013; 24(4): 248-252.

[18] Mikova O, Yakimova R, Bosmans E. Increased serum tumor necrosis factor alpha concentrations in major depression and multiple sclerosis. Eur Neuropsychopharmacol. 2001; 11: 203-208.

[19] Ferenci P, Staufer K. Depression in chronic hepatitis: the virus, the drug, or the ethnic background? Liver International 2008; 28(4): 429-431.

[20] Marcellin P, Lau GKK, Zeuzem S, et al. Comparison of safety, tolerability and quality of life in patients with chronic hepatitis $B$ versus chronic hepatitis $C$ treated with peginterferon alfa-2a (40 KD). Liver Int 2008; 28: 474-482i

[21] Bayley JP, Ottenhoff THM, Verweij CL Is there a future for TNF promoter polymorphisms? Genes and Immunity 2004; 5: 315-329.

[22] Louis E, Franchimont D, Piron A, et al. Tumour necrosis factor (TNF) gene polymorphism influences TNF-alpha production in lipopolysaccharide (LPS)-stimulated whole blood cell culture in healthy humans. Clin Exp Immunol 1998; 113: 401-406.

[23] Wilson AG, Symons JA, McDowell TL, et al. Effects of a polymorphism in the human tumor necrosis factor alpha promoter on transcriptional activation. Proc Natl Acad Sci USA 1997; 94: 3195-3199.

[24] İnkaya, AÇ, Türk Arıbaş, E., Erayman, İ, et al. Association of tumor necrosis factor alpha -238G/A and -308G/A promotor polymorphisms with clearance of Hepatitis $B$ virus infection in Turkish population. Acta Medica 2019; 50(1), 1-6. 